\title{
In situ Heating Studies of Flux Grown Barium Titanate Thin Films
}

\author{
M. J. Burch, D. Harris, R. M. White, A. Moballegh, J. Li, J. P. Maria, E. C. Dickey \\ North Carolina State University, Raleigh, NC 27606
}

The crystallization and microstructural evolution of barium titanate $\left(\mathrm{BaTiO}_{3}\right)$ thin films were studied by ex situ and in situ TEM. Previous investigations illustrated that the addition of a boron-based glass flux, $\mathrm{BaO} \cdot \mathrm{B}_{2} \mathrm{O}_{3}(\mathrm{BBO})$, improved electrical properties, such as improved tunability, which was hypothesized to be the result of less porosity and larger grains than without BBO addition[1].

To investigate the effects of $\mathrm{BBO}$ addition, ex situ studies were performed by depositing $\mathrm{BaTiO}_{3}$ $(0 \%$ and $5 \% \mathrm{BBO})$ via pulsed laser deposition onto sapphire substrates. The thin films were annealed for $1 \mathrm{hr}$. at $900^{\circ} \mathrm{C}$ and then thinned mechanically (cross section view) to electron transparency. Materials with 5\% BBO addition exhibited highly dense films with moderately sized $(121 \mathrm{~nm})$, well-formed grains, as shown in figure $2 \mathrm{a}$. This was contrasted by materials with $0 \%$ flux addition, shown in figure $1 \mathrm{a}$, which had smaller grains $(56 \mathrm{~nm})$ than the material with $5 \% \mathrm{BBO}$ and more significant porosity.

In situ heating studies were performed with a custom Protochips Aduro ${ }^{\mathrm{TM}}$ TEM holder and Protochips Aduro ${ }^{\mathrm{TM}}$ heating "e-chips," which resistively heat a ceramic membrane topped with a holey carbon film. $\mathrm{BaTiO}_{3}$ films with $0 \%$ and $3 \% \mathrm{BBO}$ addition were deposited directly on holey carbon films and heated in the TEM. As can be seen in the diffraction patterns of figures $1 \mathrm{~b}$ and $2 \mathrm{~b}$, both samples were amorphous as deposited even though they appear to be nanostructured. Samples were annealed by increasing the temperatures in $20^{\circ} \mathrm{C}$ intervals. Crystallization events were observed in both samples around $760^{\circ} \mathrm{C}$, as in shown figures $1 \mathrm{c}$ and $2 \mathrm{c}$. Islands appeared to form in materials with $3 \% \mathrm{BBO}$, though it is not yet understood the cause of this behavior. Both $0 \%$ and $3 \%$ $\mathrm{BBO}$ materials were then annealed at $1100^{\circ} \mathrm{C}$ for 6 and 8 minutes, respectively.

The annealed materials, shown in figures $1 \mathrm{~d}$ and $2 \mathrm{~d}$, had strikingly different microstructures. Grains within $0 \% \mathrm{BBO}$ samples coarsened significantly, leading to large amounts of porosity. Conversely, the $3 \% \mathrm{BBO}$ materials remained continuous. This difference in annealing behavior was attributed to flux addition slowing initial grain growth in the 3\% sample, which results in the lack of the pores like those seen in the $0 \%$ sample. The fact that the film with flux is more continuous than that without flux is consistent with the ex situ studies. However, the fact that the grains in the non-fluxed samples grew larger than those in the fluxed samples seems contradictory to the previous ex situ studies. This discrepancy is still being investigated and is believed to be the result of different annealing conditions during the ex situ and in situ studies, as well as the different mechanical boundary conditions of the annealing processes.

To investigate samples similar to materials produced for device applications, studies on FIB prepared thin film cross sections are currently underway. The FIB is utilized to prepare electron transparent cross sections of $\mathrm{BaTiO}_{3}$ thin films, which are then placed on Protochips Arduro ${ }^{\mathrm{TM}}$ heating chips. These experiments will allow for the cross-sectional observation of crystallization mechanisms in the thin films and better understand the effects of the substrate, which may act as a heterogeneous nucleation site for the crystallizing film[2]. 


\section{References}

[1] Ihlefeld, J. F. "Synthesis and Properties of Barium Titanate Solid Solution Thin Films on Copper Substrates," 2006.

[2] Project supported by the US DOD MicroElectronics Activity (H94003-10-0-1002).

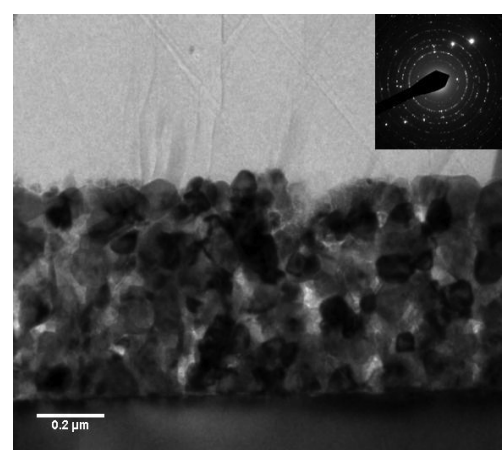

Figure 1a: 0\% $\mathrm{BBO} \mathrm{BaTiO}_{3}$ on Sapphire substrate. Annealed for $1 \mathrm{hr}$. at $900^{\circ} \mathrm{C}$.

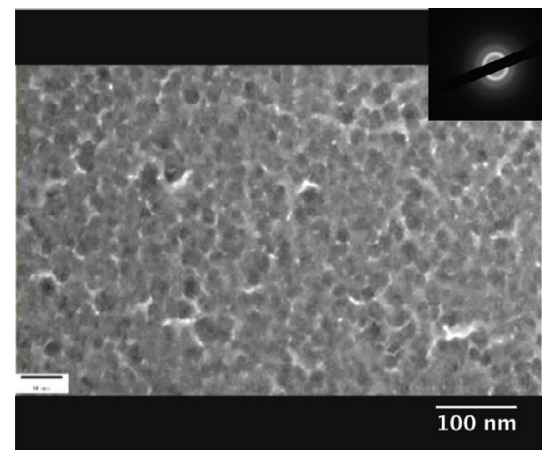

Figure 1b: Amorphous 0\% $\mathrm{BBO} \mathrm{BaTiO}_{3}$ on Echip. With carbon support underneath.

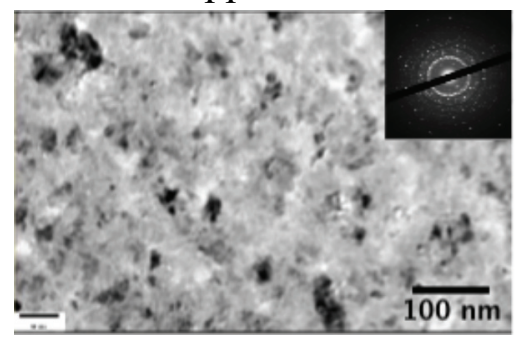

Figure 1c: $0 \% \mathrm{BBO} \mathrm{BaTiO}_{3}$ immediately after crystallization at $760^{\circ} \mathrm{C}$.

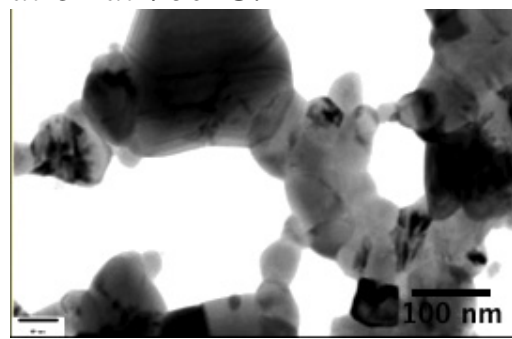

Figure 1d: $0 \% \mathrm{BBO} \mathrm{BaTiO}_{3}$ after annealing at $1100^{\circ} \mathrm{C}$ for 6 minutes.

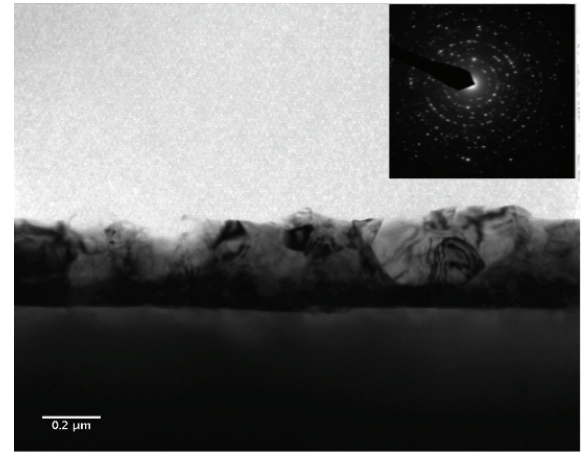

Figure 2a: $5 \% \mathrm{BBO} \mathrm{BaTiO}_{3}$ on Sapphire substrate. Annealed for $1 \mathrm{hr}$. at $900^{\circ} \mathrm{C}$.

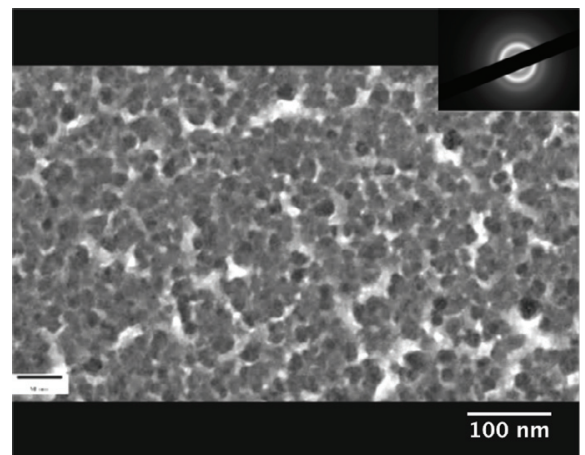

Figure 2b: Amorphous 3\% $\mathrm{BBO} \mathrm{BaTiO}_{3}$ on Echip with carbon support underneath.

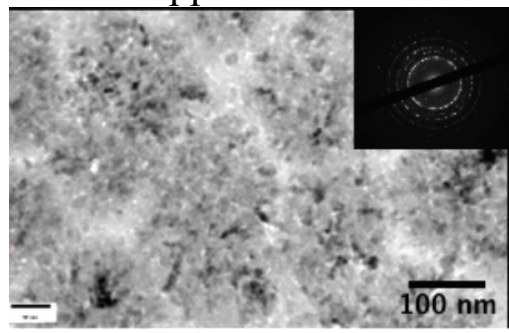

Figure 2c: $3 \% \mathrm{BBO} \mathrm{BaTiO}_{3}$ immediately after crystallization at $760^{\circ} \mathrm{C}$.

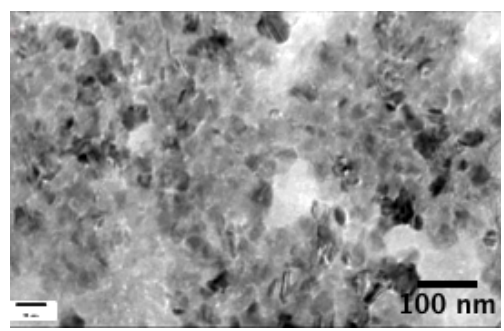

Figure 2d: $3 \% \mathrm{BBO} \mathrm{BaTiO}_{3}$ after annealing at $1100^{\circ} \mathrm{C}$ for 8 minutes. 